\title{
Cellulosic Films Obtained from the Treatment of Sugarcane Bagasse Fibers with $N$-methylmorpholine- $N$-oxide (NMMO)
}

\author{
Denise S. Ruzene • Daniel P. Silva • António A. Vicente • \\ José. A. Teixeira • Maria T. Pessoa de Amorim • \\ Adilson R. Gonçalves
}

Received: 22 May 2008 / Accepted: 16 January 2009 /

Published online: 13 February 2009

(C) Humana Press 2009

\begin{abstract}
Ethanol/water organosolv pulping was used to obtain sugarcane bagasse pulp that was bleached with sodium chlorite. This bleached pulp was used to obtain cellulosic films that were further evaluated by Fourier transform infrared (FTIR) spectroscopy, thermogravimetric analysis (TGA), and scanning electron microscopy (SEM). A good film formation was observed when temperature of $74{ }^{\circ} \mathrm{C}$ and baths of distilled water were used, which after FTIR, TGA, and SEM analysis indicated no significant difference between the reaction times. The results showed this to be an interesting and promising process, combining the prerequisites for a more efficient utilization of agro-industrial residues.
\end{abstract}

Keywords Agro-industrial residue $\cdot$ Sugarcane bagasse $\cdot$ Cellulose fiber $\cdot$ Cellulose film · NMMO

\section{Introduction}

Due to the growing emphasis on decreasing pollutant emissions, there has been significant scientific and technological interest in the development of nonpolluting processes based on the use of organic solvent of cellulose [1].

Sugarcane bagasse, a residue obtained after the manufacture of sugar and ethanol, is the most abundant lignocellulosic residue in Brazil. According to Sun et al. [2], in general,

D. S. Ruzene $(\bowtie) \cdot$ A. R. Gonçalves

Department of Biotechnology, Engineering School of Lorena, University of São Paulo, P.O. Box 116, 12602-810 Lorena, São Paulo, Brazil

e-mail: ruzeneds@hotmail.com

D. S. Ruzene $\cdot$ D. P. Silva $\cdot$ A. A. Vicente $\cdot$ J. A. Teixeira

IBB - Institute for Biotechnology and Bioengineering, Center of Biological Engineering,

University of Minho, Campus de Gualtar, 4710-057 Braga, Portugal

M. T. Pessoa de Amorim

Department of Textile Engineering, Center of Science and Textile Technology, University of Minho, 4800-058 Guimarães, Portugal 
1 ton of sugarcane generates $280 \mathrm{~kg}$ of bagasse; thus, with one production of about $455 \times$ $10^{6}$ ton of sugarcane, Brazil produced $127 \times 10^{6}$ ton of bagasse during the year 2006 [3]. Although most of the bagasse has been employed in the sugarcane industry to generate energy, there is a surplus of this agro-industrial residue, and several alternatives for its utilization have been evaluated, among which the production of animal feed, ethanol, paper, enzymes, and food additives, without impacts on the food and feed production or even damaging effects on native forests. Sugarcane bagasse is constituted by three main components: cellulose, lignin, and hemicelluloses [4].

Organosolv processes, pulping procedures utilizing aqueous organic solvents, have been extensively studied in the last 30 years as an alternative to chemical processes of pulping [5-9]. These processes can collaborate largely to the decrease of the environmental impact caused by conventional delignification processes, besides allowing for the integral use of lignocellulosic components in chemical products of commercial interest $[6,10,11]$. The ethanol/water process combines high efficiency, low cost, and ethanol abundance, an advantage in countries where sugar cane is economically important $[6,7,12]$.

Cellulose is a linear and high-molecular-weight polymer as well as natural, renewable, and biodegradable material [13]. Because of its intermolecular and intramolecular hydrogen bonds, cellulose is not dissolved by common solvents [14] but is dissolved by systems which include heavy metal-amine complex solutions, concentrated metal salts, cold $\mathrm{NaOH}$ solutions, thiocyanate/amine, $\mathrm{LiCl} /$ dimethylacetamide, $N$-methylmorpholine- $N$-oxide (NMMO)/ $\mathrm{H}_{2} \mathrm{O}$ system, and concentrated $\mathrm{H}_{2} \mathrm{SO}_{4}$ and $\mathrm{H}_{3} \mathrm{PO}_{4}[15,16]$.

The cellulose fibers produced by direct dissolution of cellulose in NMMO have the generic name of lyocell [17, 18]. This process is environmentally benign because the nontoxic NMMO solvent is used and almost all the solvent used is totally recycled [19]. Lyocell fiber production should be an entirely physical process that does not cause chemical changes in the pulp or solvent. However, there are several side reactions and considerable by-product formation in the system cellulose/NMMO/water which can cause harmful effects, such as degradation of cellulose, pronounced decomposition of NMMO, and decreased product performance. Very few chemicals are applied, and, in the idealized case, NMMO and water are completely recycled, which is also an important economic factor [18].

The dissolution of cellulose in NMMO/water mixtures is a physical process that does not require chemical derivatization of the solute $[18,20]$. However, the processes occurring at the molecular level during dissolution of cellulose in NMMO remain largely unknown. Swelling and dissolution of cellulose must be caused by rearrangement of the hydrogen bond networks in the system, meaning breakage of intramolecular and intermolecular $\mathrm{H}$ bonds in cellulose and in $\mathrm{NMMO} /$ water, with concomitant formation of new $\mathrm{H}$ bonds between solvent and cellulose [16, 20].

The present study describes the application of NMMO in sugarcane bagasse pulp that was obtained by ethanol/water organosolv process under basic conditions and bleached with sodium chlorite. This bleached pulp was used to obtain cellulosic films that were studied by Fourier transform infrared (FTIR) spectroscopy, thermogravimetric analysis (TGA), and scanning electron microscopy (SEM). FTIR spectroscopy has been largely used for the characterization of lignocellulosic materials and studied in some works involving characterization of the compounds with or without modification [21]. SEM is one of the most versatile techniques available for the analysis of the microstructural characteristics of solid objects and permits the observation and characterization of heterogeneous organic and inorganic materials on nanometer $(\mathrm{nm})$ to micrometer $(\mu \mathrm{m})$. 


\section{Materials and Methods}

Ethanol Pulping Procedure

Pulping of sugarcane bagasse with ethanol/water 1:1 $(v / v)$ mixture was carried out in a closed and pressurized vessel using $\mathrm{NaOH}\left(5 \%\right.$ dry bagasse) at $185{ }^{\circ} \mathrm{C}$ for $3 \mathrm{~h}$. The products were filtered and the pulp was dried for determination of yield.

\section{Pulp Bleaching Procedure}

Dried and refined pulps were suspended in water (3\% consistency) and heated to $70 \pm 5{ }^{\circ} \mathrm{C}$. Sodium chlorite and glacial acetic acid were added 2.5:1 $(w / v)$. The solution was further heated to $70 \pm 5{ }^{\circ} \mathrm{C}$ for $60 \mathrm{~min}$. The samples were cooled in ice bath to $10^{\circ} \mathrm{C}$. Bleached pulp was filtered, washed with distilled water, and dried [22].

\section{Analyses and Chemical Composition of the Pulp}

Kappa number and viscosity of the pulp were determined by standard methods [23, 24]. One gram of dry pulp was treated with $10 \mathrm{~mL}$ of $72 \% \mathrm{H}_{2} \mathrm{SO}_{4}$ under stirring at $45{ }^{\circ} \mathrm{C}$ for $7 \mathrm{~min}$. The flask was autoclaved for $30 \mathrm{~min}$ at 1.05 bar for the complete hydrolysis of oligomers. After filtration through a Sep-Pak C18 cartridge to remove aromatic compounds, the hydrolysate was analyzed in an Aminex HPX-87 H column $(300 \times$ $7.8 \mathrm{~mm}^{2}$, Bio-Rad) at $45{ }^{\circ} \mathrm{C}$ using a Shimadzu chromatograph with refractive-index detector. The mobile phase was $0.005 \mathrm{~mol} / \mathrm{L} \mathrm{H}_{2} \mathrm{SO}_{4}$ at $0.6-\mathrm{mL} / \mathrm{min}$ flow rate. Sugar concentrations, reported as glucan and xylan, were determined from calibration curves obtained with pure compounds. Lignin was determined by gravimetric analysis [25]. All experiments were performed in triplicate.

\section{Determination of Brightness}

The brightness of pulps was determined in agreement with the Technical Association of the Pulp and Paper Industry (TAPPI) [26]. Samples were prepared following the TAPPI norm [27]. After $24 \mathrm{~h}$, the sheets with thickness between 310 and $315 \mathrm{~g} / \mathrm{m}^{2}$ were analyzed using Photovolt 577 equipment. The reflection percentage was determined at five different points and the results were presented as average values.

\section{Film Preparation}

Samples of $0.5 \mathrm{~g}$ of bleaching pulp were transferred to $100-\mathrm{mL}$ flasks and put in a water bath at $74{ }^{\circ} \mathrm{C}$. Then, $2.5 \mathrm{~g} \mathrm{H}_{2} \mathrm{O}$ and $13.7 \mathrm{~g} \mathrm{NMMO}$ were added. The film preparation was started when the temperature reached $74{ }^{\circ} \mathrm{C}$ and nitrogen was added, for 1.5 and $2.5 \mathrm{~h}$. After the indicated period of reaction, samples were removed with a wide spatula and put on a Teflon plate $(9 \times 5 \mathrm{~cm})$ and cast as a film $(3 \times 1 \mathrm{~cm})$ that was washed in two consecutive baths of distilled water. Films were dried at room temperature for $24 \mathrm{~h}$ and put under vacuum to dry at $35{ }^{\circ} \mathrm{C}$ for $4 \mathrm{~h}$. Other two samples were heated at $50{ }^{\circ} \mathrm{C}$ (after dissolving at $74{ }^{\circ} \mathrm{C}$ ) and were cooled down to room temperature without the aid of the distilled water baths. The NMMO used was 4-methylmorpholine-4-oxide monohydrate (Sigma). 
Fourier Transform Infrared of Samples

FTIR spectra of samples were obtained on a Fourier transform infrared spectrophotometer (ABB FTLA 2000) operating at $4-\mathrm{cm}^{-1}$ resolutions and using a $\mathrm{KBr}$ disc containing $1 \%$ finely ground samples.

Thermogravimetric Analyzer

The thermal stability of the samples was evaluated using TGA on a thermal analyzer (TGA50 Shimadzu, Japan). The apparatus was continually flushed with nitrogen. The samples weighed between 10 and $12 \mathrm{mg}$ and were run from room temperature to $580{ }^{\circ} \mathrm{C}$ at a rate of $10{ }^{\circ} \mathrm{C} / \mathrm{min}$.

\section{Scanning Electron Microscopy}

The samples of sugarcane bagasse and unbleached and bleached pulp were mounted on stubs, freeze-dried, coated with gold, examined, and photographed in a scanning electron microscope SEM/EDS:JEOL JSM 6301F/Oxford INCA Energy 350. The micrographs of NMMO and films were obtained by scanning electron microscopy in low vacuum using a microscope FEI Quanta 400FEG.

\section{Results and Discussion}

The composition results based on dried weight of the sugarcane bagasse, original pulp (unbleached), and bleached pulps are listed in Table 1. Sugarcane bagasse material was characterized by its high lignin content $(28 \% w / w)$, which was two and four times higher than that of the unbleached and bleached pulps, respectively. However, ethanol/water pretreatment of original (unbleached pulp) and bleached pulps from sugarcane bagasse removed a significant amount of lignin (48\% and 76\%, respectively). The kappa number of the unbleached pulp was high $(\cong 46)$, indicating that the lignin present in the pulp was not removed after the pulping process. On the other hand, bleached pulp presented a low kappa number (micro-kappa number of 2.4). Viscosity of bleached pulp was lightly decreased after bleaching (from 8.1 to $7.8 \mathrm{cPa}$ ), indicating that the average cellulose chain length (polymerization degree) was less reduced [21]. The brightness of bleached pulps increased 2.5 times after bleaching using chlorite and $69.5 \%$ is a good value for brightness

Table 1 Chemical composition of sugarcane bagasse, unbleached pulp, and bleached pulp.

\begin{tabular}{llrr}
\hline Component & \multicolumn{2}{l}{ Composition } & \\
\cline { 2 - 4 } & Sugarcane bagasse & Unbleached pulp & Bleached pulp \\
\hline Glucan (\%) & $43.7 \pm 0.9$ & $55.7 \pm 0.6$ & $64.6 \pm 0.5$ \\
Hemicellulose (\%) & $23.7 \pm 0.5$ & $23.2 \pm 0.5$ & $21.9 \pm 0.5$ \\
Total lignin (\%) & $28.1 \pm 1.9$ & $14.6 \pm 0.9$ & $6.6 \pm 0.5$ \\
Kappa number & - & $46.2 \pm 0.6$ & $2.4 \mathrm{a} \pm 0.2$ \\
Viscosity (cPa) & - & $8.1 \pm 0.2$ & $7.8 \pm 0.3$ \\
Brightness (\%) & - & $27.1 \pm 0.8$ & $69.5 \pm 1.6$ \\
\hline
\end{tabular}

${ }^{\text {a }}$ Micro-kappa number 
considering both pulping and bleaching processes. Shatalov and Pereira [28] achieved $76.4 \%$ brightness in an organosolv pulp from Arundo donax after hydrogen peroxide bleaching.

Subsequently, the bleached ethanol/water pulp obtained in this work was used to obtain cellulosic films with NMMO. The present work presents the results of two different treatments of film: (1) at $74{ }^{\circ} \mathrm{C}$ for 1.5 and $2.5 \mathrm{~h}$, with subsequent wash in distilled water (films 1 and 2, respectively); and (2) at $50{ }^{\circ} \mathrm{C}$ for 1.5 and $2.5 \mathrm{~h}$ and cooled down to room temperature without bath of distilled water (films 3 and 4, respectively). We chose two methods of film preparation because it was observed that when we used water bath the film did not crystallized and when we did not use water bath crystallized. We saw the simple formation of the film with water bath and without water bath crystallization occurring. The film obtained after treatment at $50{ }^{\circ} \mathrm{C}$ for $2.5 \mathrm{~h}$ crystallized, while for one carried out at $1.5 \mathrm{~h}$ the pulp was not dissolved and crystallized. We used $74{ }^{\circ} \mathrm{C}$ because it is the dissolution temperature of NMMO and we used $50{ }^{\circ} \mathrm{C}$ to compare the differences between these temperatures in relation to the second subject. The bleached pulp and the films obtained were analyzed by FTIR, TGA, and SEM and the results are shown in Figs. 1, 2, and 3.

\section{Fourier Transform Infrared}

Figure 1 shows the FTIR spectrum from unbleached and bleached pulps, from films obtained by NMMO, and from the NMMO reagent itself. This figure shows only the spectra between 800 and $2,000 \mathrm{~cm}^{-1}$ because no changes are observed in the interval of 2,000-4,000 and 600-800 $\mathrm{cm}^{-1}$. According to Zhao et al. [29], strong $\mathrm{H}$ bonds form between cellulosic groups and the $\mathrm{N}-\mathrm{O}$ group of the NMMO but no significant peak shifts were observed when cellulose and NMMO mixture samples are heated at different temperatures. The same behavior was observed in the present work.

New peaks at 1,575 and $1,632 \mathrm{~cm}^{-1}$ were observed when pulp and NMMO were used. The peak at $1,632 \mathrm{~cm}^{-1}$ was assigned to $\mathrm{H}_{2} \mathrm{O}$ bonded to cellulose [30]. The peak at $1,575 \mathrm{~cm}^{-1}$ is very close to water vapor at $1,595 \mathrm{~cm}^{-1}$ [29]. The peak at $1,600 \mathrm{~cm}^{-1}$ must be attributed to $\mathrm{H}_{2} \mathrm{O}$ molecules with almost no hydrogen bonding; it is known that cellulose molecules compete with $\mathrm{H}_{2} \mathrm{O}$ molecules that are bonded to NMMO. This means that some

Fig. 1 FTIR spectra of unbleached pulp (line 1), bleached pulp (line 2), NMMO (line 3), film 1 with $1.5 \mathrm{~h}$ of treatment (line 4), film 2 with $2.5 \mathrm{~h}$ of treatment (line 5), film 3 with $1.5 \mathrm{~h}$ of treatment without bath (line 6), and film 4 with $2.5 \mathrm{~h}$ of treatment without bath (line 7)

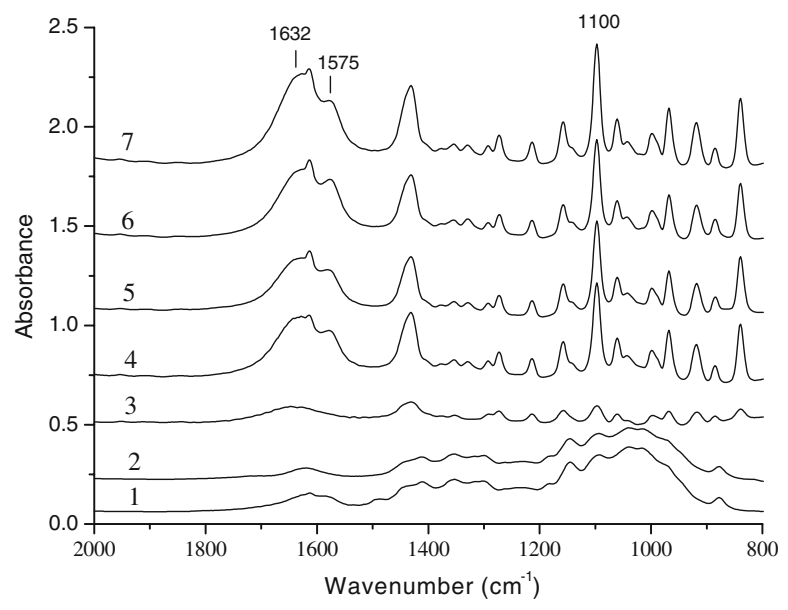




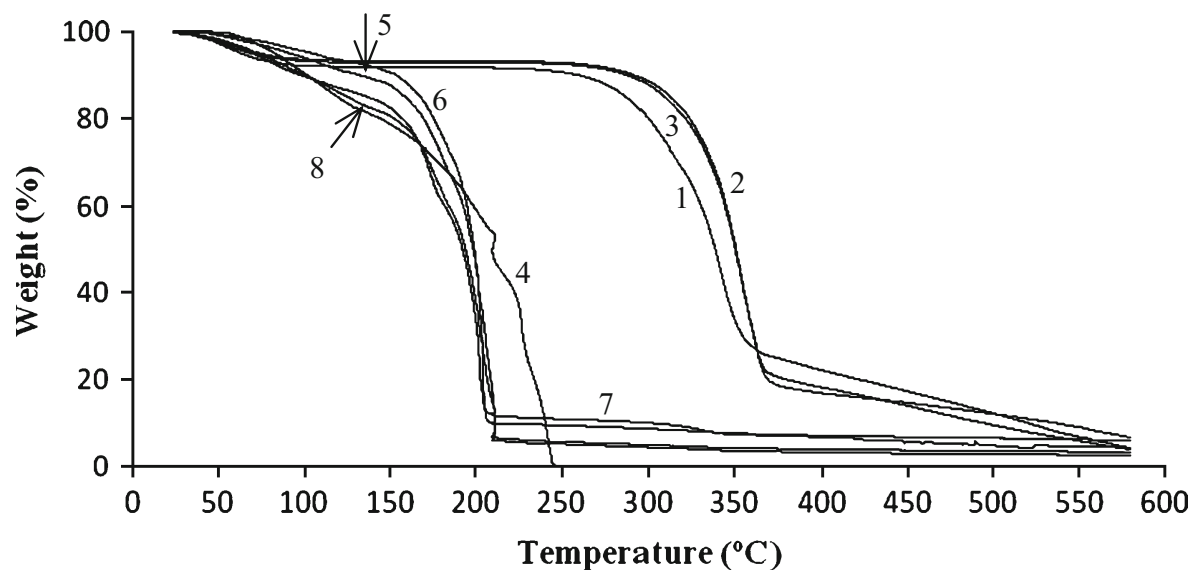

Fig. 2 TGA curves of sugarcane bagasse (line 1), unbleached pulp (line 2), bleached pulp (line 3), NMMO (line 4), film 1 with $1.5 \mathrm{~h}$ of treatment (line 5), film 2 with $2.5 \mathrm{~h}$ of treatment (line 6), film 3 with $1.5 \mathrm{~h}$ of treatment without bath (line 7), and film 4 with 2.5 h of treatment without bath (line 8 )

$\mathrm{H}_{2} \mathrm{O}$ molecules may be replaced by cellulose molecules and the other part of released $\mathrm{H}_{2} \mathrm{O}$ molecules is physically confined in the cellulose matrix and forms no or very weak hydrogen bonds with cellulose. The peak at $1,100 \mathrm{~cm}^{-1}$ is typical for ether bonds and not much specific for different sources. But it is seen that in films this band is higher in
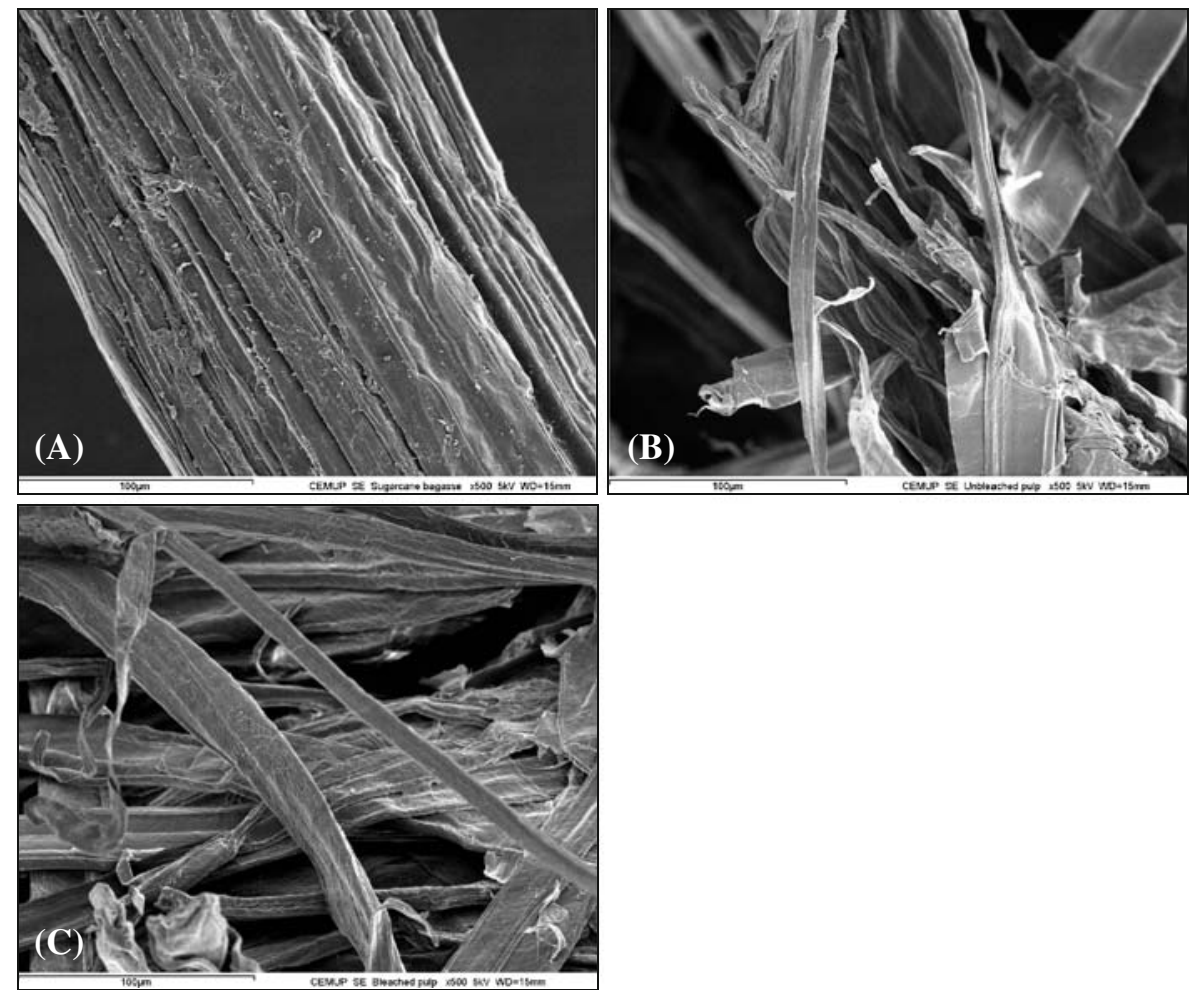

Fig. 3 Scanning electron microscopy of sugarcane bagasse (a), unbleached pulp (b), and bleached pulp (c) 
comparison with the band in NMMO or in pulps, giving indication of an etherification that can occur in the film prepared.

\section{Thermogravimetric Analysis}

TGA is an analytical technique used to determine a material's thermal stability and its fraction of volatile components by monitoring the weight change that occurs when a sample is heated. Synthetic and natural polymers are subject to a degradation of the mechanical properties under the influence of increased temperatures [31]. In this work, the thermal properties (Fig. 2) of sugarcane bagasse (line 1), unbleached pulp (line 2), bleached pulp (line 3), NMMO (line 4), film 1 with $1.5 \mathrm{~h}$ of treatment (line 5), film 2 with $2.5 \mathrm{~h}$ of treatment (line 6), film 3 with $1.5 \mathrm{~h}$ of treatment without bath (line 7), and film 4 with $2.5 \mathrm{~h}$ of treatment without bath (line 8 ) were studied by TGA.

Figure 2 and Table 2 show the TGA results obtained from sugarcane bagasse fibers and films obtained by using NMMO. In general, there are three stages of degradation in the TGA curves of natural fiber samples. The initial weight loss of fibers $\left(100-150{ }^{\circ} \mathrm{C}\right)$ is due to evaporation of the adsorbed moisture. This loss depends on the initial moisture content of the fibers. The second severe weight loss $\left(250-350{ }^{\circ} \mathrm{C}\right)$ and the third stage are due to decomposition of the major components of the fibers. These results are consistent with the data reported in the literature [32,33]. The higher onset of degradation temperatures indicates the improvement of the material's thermal stability. These results clearly illustrate that the thermal stability of the sugarcane bagasse fibers increases after chemical treatment. The lower thermal stability of the untreated fibers relative to chemically treated fibers is attributed to the higher lignin content in the raw material [33, 34].

The degradation temperature of the NMMO and also of the films reached $160{ }^{\circ} \mathrm{C}$. The decrease in the onset value of NMMO and films can be attributed to the decrease in the crystallinity of the fibers after chemical treatment using NMMO and also means a decrease of the stability of the mixture (bleached pulp and NMMO). There is also a little distinction between the amounts of the residues remaining after heating of $560{ }^{\circ} \mathrm{C}$ heating. All samples have a residual weight between $0.35 \%$ and $5.9 \%$ at $560{ }^{\circ} \mathrm{C}$ (Table 2).

Under an inert atmosphere, the final products from degradation of cellulose are carbonaceous residues plus intact fibers when they do not remain after heating [35]. During the plant growth, inorganic compounds are needed as nutrients, and these inorganic compounds will generate ash. Samples of sugarcane bagasse and pulps were found to be initially degraded at about $260{ }^{\circ} \mathrm{C}$ whereas NMMO and films obtained by NMMO would be degraded at about $160{ }^{\circ} \mathrm{C}$. Maximum rates of weight loss were observed between 260

Table 2 Degradation characteristics of the sugarcane bagasse fibers, NMMO, and films obtained by NMMO

\begin{tabular}{lcc}
\hline Samples & Onset of degradation $\left({ }^{\circ} \mathrm{C}\right)$ & Residue after $560{ }^{\circ} \mathrm{C}(\%)$ \\
\hline Sugarcane bagasse & 320 & 5.9 \\
Unbleached pulp & 339 & 5.2 \\
Bleached pulp & 337 & 8.1 \\
NMMO & 217 & 0.3 \\
Film 1 & 187 & 2.6 \\
Film 2 & 183 & 6.1 \\
Film 3 & 182 & 4.8 \\
Film 4 & 187 & 3.5 \\
\hline
\end{tabular}


and $360{ }^{\circ} \mathrm{C}$ for sugarcane bagasse and pulps and between 160 and $240{ }^{\circ} \mathrm{C}$ for NMMO and films. As observed, sugarcane bagasse and pulps were stable up to $250{ }^{\circ} \mathrm{C}$ (lines $1-3$ ), whereas NMMO and films were stable up to $150{ }^{\circ} \mathrm{C}$ (lines 4-8). Beyond these temperatures, thermal degradation takes place. As can be seen (Fig. 2), for a $30 \%$ weight
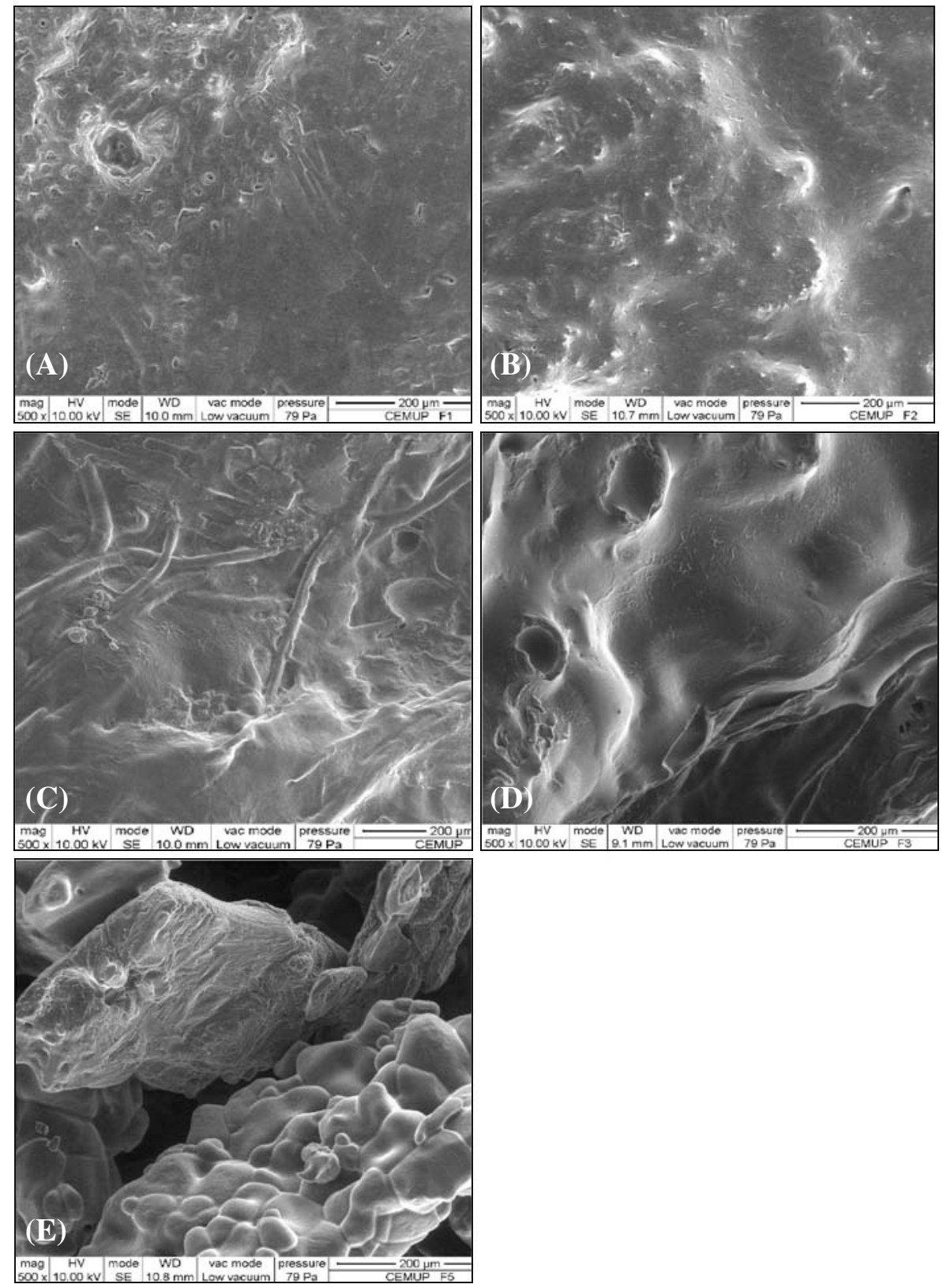

Fig. 4 Scanning electron microscopy of film 1 with $1.5 \mathrm{~h}$ of treatment (a), film 2 with $2.5 \mathrm{~h}$ of treatment (b) at $74{ }^{\circ} \mathrm{C}$, film 3 with $1.5 \mathrm{~h}$ of treatment without bath (c), film 4 with $2.5 \mathrm{~h}$ of treatment without bath (d) at $50{ }^{\circ} \mathrm{C}$ and $\mathrm{NMMO}(\mathbf{e})$ 
loss, the decomposition temperatures of the degraded samples occurred at $175^{\circ} \mathrm{C}$ (lines 7-8), $186{ }^{\circ} \mathrm{C}$ (line 4), $190{ }^{\circ} \mathrm{C}$ (line 5), $195{ }^{\circ} \mathrm{C}$ (line 6), $320{ }^{\circ} \mathrm{C}$ (line 1), and $340{ }^{\circ} \mathrm{C}$ (lines 2-3).

\section{Scanning Electron Microscopy}

The influence of the pulping process as well as of the bleaching process in the structure of the sugarcane bagasse particle can be observed in Fig. 3. In this figure, the sugarcane bagasse in the original form (Fig. 3a) and the unbleached pulp (Fig. 3b) shows that the pulping promoted the rupture and solubility of the lignin to the liquor that generated a cellulose-rich solid residue. The lignin removal, after bleaching, permitted the separation of the cellulose fibers, as can be visualized in Fig. 3c. Surface and cross-sectional morphologies of cellulose films were investigated under different conditions.

Figure 4 shows the surface morphologies of cellulose films taken by SEM. When cellulose films were washed in water bath, a good formation of film without rough surfaces and homogeneous structures was observed as shown in Fig. $4 \mathrm{a}\left(1.5 \mathrm{~h}\right.$ and $\left.74{ }^{\circ} \mathrm{C}\right)$ and Fig. $4 \mathrm{~b}$ $\left(2.5 \mathrm{~h}\right.$ and $\left.74^{\circ} \mathrm{C}\right)$, while films that were not washed in water bath show a surface roughness with a layered structure Fig. $4 \mathrm{c}\left(1.5 \mathrm{~h}\right.$ and $\left.50{ }^{\circ} \mathrm{C}\right)$ and with fibers of bleached pulp still undissolved Fig. $4 \mathrm{~d}\left(2.5 \mathrm{~h}\right.$ and $\left.50^{\circ} \mathrm{C}\right)$. In this case (Fig. $\left.4 \mathrm{c}\right)$, it is possible to see some fibres in the film; this could be due to the temperature being too low that did not dissolve the pulp at $50{ }^{\circ} \mathrm{C}$.

\section{Conclusions}

A good formation of film was observed without rough surfaces and originating homogeneous structures. TGA analyses show that the decrease in the onset value of NMMO and films can be attributed to the decrease in the crystallinity of the fibers after chemical treatment using NMMO; this means a decreased stability of the mixture (bleached pulp and NMMO). FTIR results suggest that the released $\mathrm{H}_{2} \mathrm{O}$ molecules exist both adsorbed and physically confined in the cellulose matrix. The techniques studied furnish information on the properties of the material and, when possible, making correspondence between themselves. Thus, the process presented in this work showed to be interesting and promising, combining the prerequisites for a more efficient utilization of agro-industrial residues.

Acknowledgements The authors acknowledge the financial support from Fundação de Amparo à Pesquisa do Estado de São Paulo (FAPESP), Conselho Nacional de Desenvolvimento Científico e Tecnológico (CNPq), and Coordenação de Aperfeiçoamento de Pessoal de Nível Superior (CAPES), Brazil, as well as the Fundação para a Ciência e a Tecnologia (FCT) and CEMUP financial support ref ${ }^{a}$ REEQ/1062/CTM/2005 and REDE/1512/RME/2005-Fundação para a Ciência e Tecnologia (FCT), Portugal.

\section{References}

1. Chegolya, A. S., Grinshpan, D. D., \& Burd, E. Z. (1989). Textile Research Journal, 59, 501-506. doi:10.1177/004051758905900902.

2. Sun, X. J., Sun, X. F., Sun, R. C., \& Su, Y. Q. (2004). Carbohydrate Polymers, 56, 195-204. doi:10.1016/j.carbpol.2004.02.002.

3. FAO, Food and Agriculture Organization of the United Nations. (2008) FAOSTAT statistics database. http://faostat.fao.org/site/567/DesktopDefault.aspx?PageID=567 (last updated 21 May 2008). 
4. Fengel, D., \& Wegener, G. (1989). Wood: Chemistry, ultrastructure, reactions. New York: Walter de Gruyter.

5. Kleinert, T. N. (1974). TAPPI Journal, 57, 99-102.

6. Aziz, S., \& Sarkanen, K. (1989). TAPPI Journal, 72, 169-175.

7. Young, R. A., \& Akhtar, M. (1998). Environmentally friendly technologies for the pulp and paper industry. New York: Wiley.

8. Gonçalves, A. R., \& Ruzene, D. S. (2001). Applied Biochemistry and Biotechnology, 91-93, 63-70. doi:10.1385/ABAB:91-93:1-9:63.

9. Gonçalves, A. R., \& Ruzene, D. S. (2003). Applied Biochemistry and Biotechnology, 105-108, $195-204$. doi:10.1385/ABAB:105:1-3:195.

10. Paszner, L., \& Cho, H. J. (1989). TAPPI Journal, 72, 135-142.

11. Bendzala, J., \& Kokta, B. V. (1995). Wood Science and Technology, 29, 467-479. doi:10.1007/ BF00194205.

12. Goyal, G. C., Lora, J. H., \& Pye, E. K. (1992). TAPPI Journal, 75, 110-116.

13. Fengel, D., \& Wegener, G. (1989). Wood chemistry, ultrastructure, reactions. Berlin: Walterde Gruyter.

14. Hon, D. N. S. (1996). Chemical modification of lignocellulosic materials. Boca Raton: CRC.

15. Johnson, D. C. (1985). Solvents for cellulose. In T. P. Nevell \& S. H. Zeronian (Eds.), Cellulose chemistry and its applications (pp. 181-201). Chichester: Ellis Horwood.

16. Zhao, H., Kwak, J. H., Wang, Y., Franz, J. A., White, J. M., \& Holladay, J. E. (2007). Carbohydrate Polymers, 67, 97-103. doi:10.1016/j.carbpol.2006.04.019.

17. Fink, H.-P., Weigel, P., Purz, H. J., \& Ganster, J. (2001). Progress in Polymer Science, 26, 1473-1524. doi:10.1016/S0079-6700(01)00025-9.

18. Rosenau, T., Potthast, A., Sixta, H., \& Kosma, P. (2001). Progress in Polymer Science, 26, 1763-1837. doi:10.1016/S0079-6700(01)00023-5.

19. Hall, M. E., Horrocks, A. R., \& Seddon, H. (1999). Polymer Degradation \& Stability, 64, 505-510. doi:10.1016/S0141-3910(98)00202-X.

20. Rosenau, T., Hofinger, A., Potthast, A., \& Kosma, P. (2003). Polymer, 44, 6153-6158. doi:10.1016/ S0032-3861(03)00663-3.

21. Ruzene, D. S., Gonçalves, A. R., Teixeira, J. A., \& Pessoa De Amorim, M. T. (2007). Applied Biochemistry and Biotechnology, 136-140, 573-582. doi:10.1007/s12010-007-9080-0.

22. Browing, B. L. (1963). The chemistry of wood (p. 574). New York: Interscience.

23. TAPPI-Technical Association of the Pulp and Paper Industry. (1985). TAPPI Standard Methods. T, 236, $\mathrm{cm}-85$.

24. TAPPI-Technical Association of the Pulp and Paper Industry. (1982). TAPPI Standard Methods. T, 230, om-82.

25. Rocha, G. J. M. (2000). Ph.D. thesis, São Carlos/Universidade de São Paulo, Brazil.

26. TAPPI-Technical Association of the Pulp and Paper Industry. (1999). TAPPI Standard Methods T, 230, om-99.

27. TAPPI-Technical Association of the Pulp and Paper Industry. (1999). TAPPI Standard Methods. T, 236, om-99.

28. Shatalov, A. A., \& Pereira, H. (2005). Bioresource Technology, 96, 865-872. doi:10.1016/j. biortech.2004.09.005.

29. Zhao, H., Kwak, J. H., Wang, Y., Franz, J. A., White, J. M., \& Holladay, J. E. (2007). Carbohydrate Polymers, 67, 97-103. doi:10.1016/j.carbpol.2006.04.019.

30. Schwanninger, M., Rodrigues, J. C., Pereira, H., \& Hinterstoisser, B. (2004). Vibrational Spectroscopy, 36, 23-40. doi:10.1016/j.vibspec.2004.02.003.

31. Wielage, B., Lampke, T., Marx, G., Nestler, K., \& Starke, D. (1999). Thermochimica Acta, 337, 169177. doi:10.1016/S0040-6031(99)00161-6.

32. Ghetti, P., Ricca, L., \& Angelini, L. (1996). Fuel, 75, 565-573. doi:10.1016/0016-2361(95)00296-0.

33. Shafizadeh, F., \& DeGroot, W. (1976). Combustion characteristics of cellulose fuels. In F. Shafizadeh, K. V. Sarkanen, \& D. A. Tillman (Eds.), Thermal uses and properties of carbohydrates and lignins. New York: Academic.

34. Hornsby, P. R., Hinrichsen, E., \& Tarverdi, K. (1997). Journal of Materials Science, 32, 443-449. doi:10.1023/A:1018521920738.

35. Devallencourt, C., Saiter, J. M., \& Capitaine, D. (1996). Polymer Degradation \& Stability, 52, $327-334$. doi:10.1016/0141-3910(95)00239-1. 